\title{
TEKNOLOJİ BAĞIMLILIĞININ BULANIK MANTIK İLE SINIFLANDIRILMASI
}

\author{
Çilem Koçak ${ }^{1 *}$, Tuncay Yiğit ${ }^{2}$
}

${ }^{1}$ Isparta University of Applied Sciences, Yalvaç Vocational School Of Technical Sciences, Isparta, Türkiye

2 Suleyman Demirel University, Engineering Faculty, Department of Computer Engineering, Isparta, Türkiye

\begin{tabular}{|c|c|}
\hline Keywords & Öz \\
\hline $\begin{array}{l}\text { Teknoloji Bağımlılı̆̆ı̆, } \\
\text { Bulanık Mantık, } \\
\text { Yapay Zeka. }\end{array}$ & 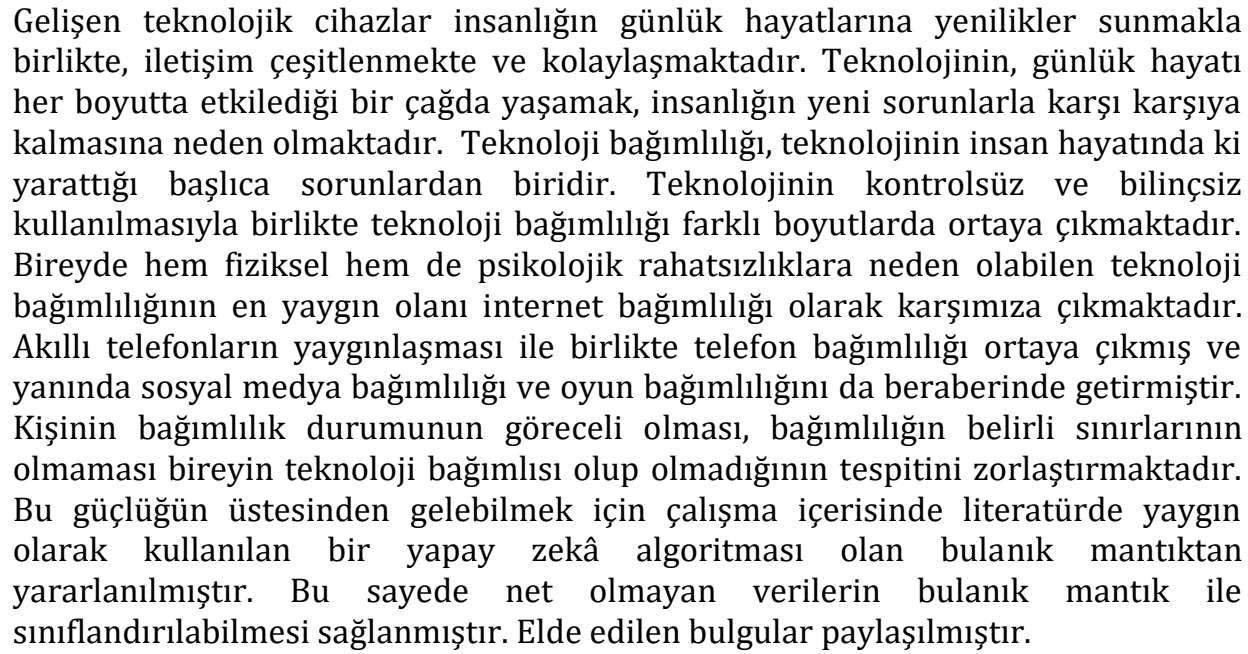 \\
\hline
\end{tabular}

\section{CLASSIFICATION OF TECHNOLOGY ADDICTION WITH FUZZY LOGIC}

\begin{tabular}{l}
\hline Anahtar Kelimeler \\
\hline Technology Addiction, \\
Fuzzy Logic, \\
Artificial Intelligence
\end{tabular}

Alıntı / Cite

Koçak, C.., Yiğit, T., (2020). Classification Of Technology Addiction With Fuzzy Logic, Journal of Engineering Sciences and Design, 8(5), 126-132.

\begin{tabular}{l|l}
\hline Yazar Kimliği / Author ID (ORCID Number) & Makale Süreci / Article Process
\end{tabular}

C.. Koçak, 0000-0002-4516-2076

T. Yiğit, $\quad 0000-0002-6741-7826$

\begin{abstract}
While evolving technological devices offer innovations to the daily lives of humanity, communication is diversifying and facilitating. Living in an age where technology affects everyday life in every dimension causes humanity to face new challenges. Technology addiction is one of the main problems of technology in human life. With the uncontrolled and unconscious use of technology, Technology addiction emerges in different dimensions. Internet addiction is the most common form of technology addiction, which can cause both physical and psychological disorders in the individual. With the spread of smartphones, phone addiction has emerged and brought with it social media addiction and game addiction. The relative status of a person's addiction and the lack of specific limits of addiction make it difficult to determine whether an individual is addicted to technology. In order to overcome this difficulty, Fuzzy Logic, an artificial intelligence algorithm commonly used in the literature, was used in this study. In this way, it is provided to classify unclear data through fuzzy logic. The findings were shared.
\end{abstract}

\footnotetext{
* ilgili yazar / Corresponding author: cilemkocak@isparta.edu.tr
} 


\section{Giriş (Introduction)}

Türkiye ve dünyada teknoloji alanındaki gelişmeler hızla ilerlemektedir. Yaşamımızın hemen her alanında bu teknolojiler önemli birer ihtiyaç olarak kullanılmaktadır. İçinde bulunduğumuz teknoloji çağı ve Endüstri 4.0 sürecinin getirisi olan teknolojinin hızlı gelişimi, insanların günlük hayatlarında yoğun olarak teknolojik araç ve ortam kullanımını beraberinde getirmiştir Her gün milyonlarca insan bilgi edinmek, sohbet etmek, maddi kazanç sağlamak, karşı cinsle ilişki başlatmak, oyun ve kumar oynamak gibi çeşitli sebeplerle internet teknolojisini kullanmaktadır. Teknoloji bağımlılığı, internet bağımlılığı, sosyal medya bağımlılığı, cep telefonu bağımlılığı ve oyun bağımlılı̆̆ gibi çeşitli kavramlarla adlandırılan ve bireyler üzerinde olumsuz etkileri bulunan bazı bağımlılık türleri bulunmaktadır (Akkaş, İ.; 2019). Literatürde teknolojik bağımlılı̆̆ının sosyal ve fiziksel sorunlara neden olduğu sonucuna ulaşılmaktadır. Teknolojinin yoğun olarak kullanımı kullanıcıların kendi çevreleri ile sosyalleşememesine ve uykusuzluk, depresyon gibi sorunları da beraberinde getirmektedir. Bu durum teknoloji bağımlılı̆̆ını yaşanılan durumlar göre internet bağımlılığı, sosyal medya bağımlılığı gibi farklı bağımlılık türleri olarak görülmektedir. Söz konusu bağımlılıkların yalnızlık, uyku kalitesi, benlik saygısı ve akademik performansı etkilediği görülmektedir (Twenge, 2017). Diğer taraftan teknoloji kullanımının bazı olumlu sonuçları da bulunmaktadır; teknoloji kullanımı dostluğu güçlendirir, kolaylaştırır kişilerarası konuşma ve iletişim ve yeni sosyal ilişsiler kurulmasına izin vermektedir (Woods HC, Scott H, 2016; Ikiz FE, Savci M, Asici E, Yoruk C 2015; Savci, M., ve Aysan, F.;2017; J Adolesc 2016).

\section{Teknoloji Bağımlılığı (Technology Addiction)}

Teknoloji bağımlılı̆̆ı madde bağımlılı̆̆ı gibi ruh halinin olumlu bir şekilde değiştirilmesi müdahalesinde belirginlik "klasik" bağımlılık belirtileri deneyimini içermektedir (Kuss ve Griffiths, 2011). Shaw ve Black (2008) teknoloji bağımlılığını; kişinin kendini rahatsız hissetmesine yol açacak şekilde ve aşırılıkla teknoloji kullanımı, kendini zayıfça kontrol edebilmek, dürtü ve eylemlerle kendini kontrol edememe biçimi olarak tanımlamışlardır (Shaw, M., ve Black, D. W. 2008). Kullanıcıların günlük olarak teknoloji kullanımına ayırdıkları vaktin artması, onların teknoloji bağımlılı̆̆ üzerinde belirleyici unsurlardan biri olmaktadır. 2019 yllı itibariyle Türkiye'de nüfusun \%96,7'sinin bilgisayara sahip olduğu bunun \%94,9'u internete bağlı olduğu görülmektedir. İnternet kullanımının artışı ile iletişim yöntemi olarak internete yönelen halkın sabit telefon hattı sayısı 2019 yılı itibariyle 11.605.347 olarak 1993 yılı seviyelerine gerilemiştir. Bunun yanı sıra cep telefonu hat sayısı da 80 milyonun üstündedir. Toplumun \%98,7'si akıllı telefon kullanmaktadır(TUIK, 2019). Türkiye internet kullanım istatistikleri dikkate alındığında internette geçirilen sürenin fazlalığı göze çarpmaktadır. Teknoloji bağımlılığında kullanılan teknolojik cihazla geçirilen sürenin fazlalığı ile birlikte kaç yıldır bu teknolojik cihazın kullanıldığı da bağımlılık düzeyi ile ilişkili olduğu görülmektedir (Aktan, E. 2018).

İnternet bağımlılığına başlama sürecinde tolerans gelişir, kullanıcı yoksunluk sendromu yaşar ve kontrol çabaları başarısız olur, kendine engel olamaz çok vakit harcanır, kontrol kalkar, çatışma yaşanır, zihinsel işlevsellik bozulur, duygu durum bozuklukları başlar kullanıcı kendine ve çevresine yalan söylemeye başlar. Akabinde uyku düzenin bozulur ve yeme alışkanlıkları değişir (Dinç, 2015).

Beard ve Wolf'un Önerdiği İnternet Bağımlılığı Tanı Ölçütlerinden 5 ölçütün hepsinin mevcut olması kişinin bağımlı olduğu sonuca ulaşıldığını göstermektedir. Bunlar; "İnternetle ilgili çok fazla zihinsel meşguliyet (bir önceki çevrim-içi etkinliğini düşünme veya sonraki çevrim-içi seansını bekleme), İnternette istenilen zevki alabilmek için gittikçe daha fazla zaman geçirme ihtiyacı hissetme, Çoğu defa başarısızlıkla sonuçlanan internet kullanımını kontrol etme veya bırakma çabası içinde bulunma, İnternet kullanımını azaltmaya ya da bırakmaya çalıştı̆̆ zamanlarda huzursuzluk hissetme, depresif olma ya da hassasiyet içinde olma, İnternette geçirmeyi düşündüğünden daha uzun zaman geçirme" olarak belirlenmiştir (Beard ve Wolf, 2001).

\section{Materyal ve Methot (Material and Method)}

Çalışmada bulanık mantık kullanılarak teknoloji kullanan bir bireyin bağımlılık durumu tespit edilmeye çalışılmıştır.

\subsection{Bulanık Mantık (Fuzzy Logic)}

Günlük hayatta kullanılan birçok terim genellikle bulanık bir yapıya sahiptir. Sayısal olarak tam ifade edilemeyen durumlarda bulanık mantık günlük hayatı sayısal ifadelere dönüştürerek bir olayı açıklarken, bir şeyi tanımlarken kolaylık sağlar. Örneğin yaşlı-genç, uzun-kısa, yavaş-hızlı ve bunların ara değerleri sözel olarak 
kullanılan terimlerdir. Günlük hayatta karşımızdaki kişinin uzun olması kişinin kendi boyundan uzun olması ile ifade edilse de karşıdaki kişi standart ölçülere göre uzun olmayabilir.

Araba ile hızlı gitmemiz gerekince arabaya biraz gaz verilir hız durumuna göre gazı biraz daha fazla vererek hızlanma sağlanabilir. Bütün bunlar insan beyninin bir bilgisayardan farklı olarak belirsiz ve kesinlik içermeyen durumlarda nasıl davrandığını ortaya sermektedir ve olayları nasıl tanımlayarak değerlendirip, komut vererek sonuçlandırdığına birer örnek teşkil etmektedir.

Bulanık mantık uzman sistemler, görüntü işleme, karar destek mekanizmalarında, bilgisayar ağları dizaynın da ve insan davranışları analizinde kullanılmaktadır (Altaş, İ. H. 1999).

Zadeh 1965 yılında duyurmuș olduğu bulanık mantık, ara değerlerin de göz önünde bulundurulması gerektiğine dikkat çekmiştir ki klasik bilgisayar mantığında " 0 ” ve "1" gibi kesin ayrımlar söz konusu olmaktadır. Lotfy A. Zadeh'ye göre, "bulanık mantık her şeyin, doğrunun da, bir derece meselesi olduğu insani akıl yürütme için bir modeldir." mantığı ile temelde, sözcükle hesaplama anlamı sunmaktadır (Zadeh, 1965,1998). Sınıfta kaç kişi okuldan memnundur sorusu sorulur kimisi tam kolunu kaldırır kimisi biraz kaldırır kimisi gönülsüz öğretmeni istediği diye kaldırır bunun sonucunda el kaldıranların okuldan memnun olduğu sonucu çıkar fakat tüm öğrencilerin okuldan yüze yüz memnuniyeti söz konusu değildir. Örnekten yola çıkarak bir bulanık kümenin hem sınırları hem bileșenleri, hem de yapısı belirsizlik göstermektedir. Yani okuldan memnun olanlar bu kümeye ait olan elemanlar veya kümeye ait olmayanlar olarak kesin bir yargıyla belirlemek mümkün değildir. Kolunu biraz kaldıran veya gönülsüz kaldıranları da bu kümeye dâhil etmek de mümkündür yâda bu öğrencileri okuldan memnun olmayanlara grubuna dâhil etmekte mümkündür. Bulanık mantıksal işlemlerde bir kümenin elemanlarının bu kümeye ait olmalarının bir sayısal değeri bulunmaktadır ve bilgisayar mantığı ile bu 0 ile 1 arasında herhangi bir değerdir. Bulanık mantığın da belli sınırları bulunmaktadır ve bu sınırlar duruma göre değişiklik gösterir. Bulanık mantığı klasik mantıktan ayıran nokta, bu sınırların daha esnek olmasıdır. Bulanık mantığın bu esnekliği sayesinde uygulandığı her alanda çok daha hassas sonuçlar ortaya çıkarmaktadır (Alan, 2003). Bulanık mantıkta temel amaç bir bilgisayarın insan gibi düşünmesini sağlamaktır. Bulanık mantık insanın karmaşık düşünmesi ve doğal dildeki belirsizlik esasına uygun davranabilen sonuçlar ortaya çıkarmaktadır. Örneğin sayısal olarak ifade edebildiğimiz havanın, günlük sıcaklık değerlerinin yorumu kişiden kișiye değișiklik gösterebilmektedir. Tablo 1'de günlük sıcaklık değerleri bulunmaktadır (Koçak Ç, 2018). Herhangi bir sıcaklık değeri birden fazla kategoride yer alabilmektedir.

Tablo 1. Bulanık Mantık Örneği

\begin{tabular}{|l|l|}
\hline Bulanık Küme & Sicaklık Aralıkları \\
\hline Çok Sıcak & $35^{\circ} \mathrm{C}$ Üstü \\
\hline Biraz Sıcak & $30-35^{\circ} \mathrm{C}$ Aralığı \\
\hline Sıcak & $22-30^{\circ} \mathrm{C}$ Aralığı \\
\hline Ilık & $18-22^{\circ} \mathrm{C}$ Aralısı \\
\hline Serin & $15-18^{\circ} \mathrm{C}$ Aralığı \\
\hline Soğuk & $10-15^{\circ} \mathrm{C}$ Aralığı \\
\hline Biraz Soğuk & $0-10^{\circ} \mathrm{C}$ Aralığ \\
\hline Çok Soğuk & $0{ }^{\circ} \mathrm{C}^{\prime}$ den Düşük \\
\hline
\end{tabular}

Bulanık mantık sistemi üç temel yapıdan oluşmaktadır. Bunlar; bulanıklaştırma, çıkarım mekanizması ve durulaştırmadır. Bulanık mantığın ilk aşaması olan bulanıklaştırmada elde edilen verilerin ara değerleri sınırlandırmakta, yani bulanıklaştırma işlemi yapılmaktadır. Sonraki aşamada ise gerekli çıkarımlar yapılarak istenilen sonuçları elde etmek için belli kurallar oluşturulur. Şekil1.'de bir bulanık mantık sisteminin akış diyagramı verilmiştir.

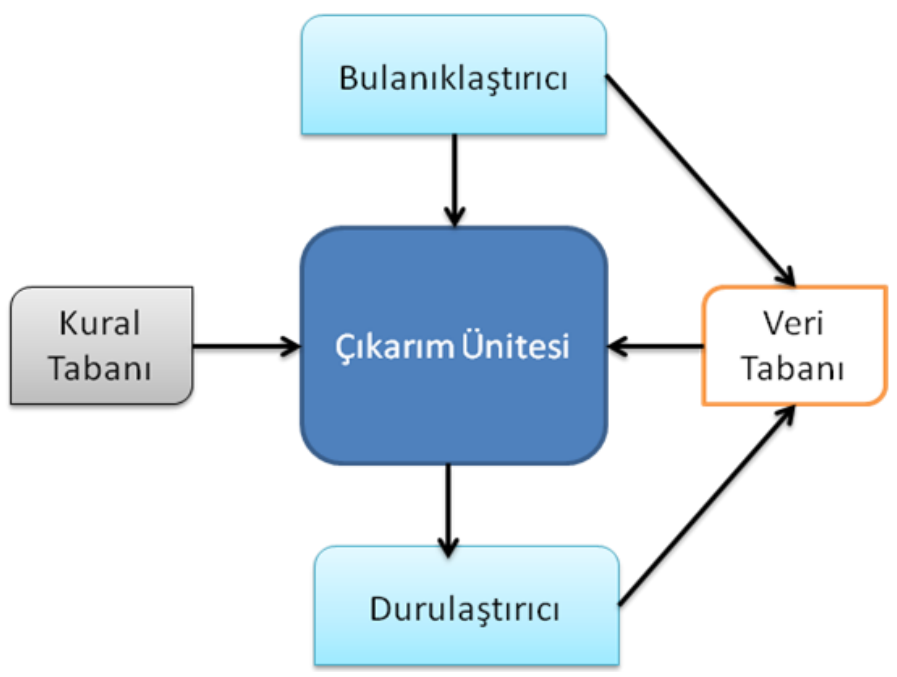

Şekil 1. Bulanık Mantık Çalıșma Mantığı 


\subsection{Bulgular (Findings)}

Veriler 18-60 yaş arası 166 gönüllü katılımcılardan elde edilmiştir. Elde edilen katılımcıların vermiş oldukları cevaplara ait frekans bilgileri sırasılyla Tablo 2, 3, 4, 5, 6' da sunulmuştur.

Tablo 2. Kullanıcının Günlük Sosyal Medya Kullanım Durumu

\begin{tabular}{|c|c|c|}
\hline $\begin{array}{l}\text { Sosyal ağlarda günde ortalama ne kadar } \\
\text { zaman geçiriyorsun? }\end{array}$ & Frekans & Yüzde (\%) \\
\hline 1 saatten az & 47 & 28,0 \\
\hline $2-3$ saat arası & 29 & 17,3 \\
\hline 4-5 saat arası & 60 & 35,7 \\
\hline 5 saatten fazla & 32 & 19,1 \\
\hline Toplam & 168 & 100,0 \\
\hline
\end{tabular}

Tablo 3. Kullanıcının Hangi Sitelerde Gezindiği Durumu (Tür Olarak)

\begin{tabular}{|c|c|c|}
\hline $\begin{array}{l}\text { Hangi tür internet sitelerinde sürekli } \\
\text { gezinirsiniz? }\end{array}$ & Frekans & Yüzde (\%) \\
\hline \begin{tabular}{|l|l|} 
& Alıșveriș \\
\end{tabular} & 83 & 49,4 \\
\hline Blog & 5 & 3,0 \\
\hline Arkadașlık & 26 & 15,4 \\
\hline Çevrim İçi Müzik /film/video & 54 & 32,1 \\
\hline Toplam & 168 & 100,0 \\
\hline
\end{tabular}

Tablo 4. Kullanıcının Çevrimiçi Oyun Oynadığı Durumu (Tür Olarak)

\begin{tabular}{|c|c|c|}
\hline $\begin{array}{l}\text { Hangi tür çevrimiçi oyunları sürekli } \\
\text { oynuyorsunuz? }\end{array}$ & Frekans & Yüzde (\%) \\
\hline \begin{tabular}{l|l|} 
& Aksiyon-Macera \\
\end{tabular} & 83 & 49,4 \\
\hline Simülasyon & 25 & 14,9 \\
\hline Savaş Strateji & 35 & 20,9 \\
\hline Bulmaca & 25 & 14,9 \\
\hline Total & 168 & 100,0 \\
\hline
\end{tabular}

Tablo 5. Kullanıcının Günlük İnternet Kullanım Durumu

\begin{tabular}{|c|c|c|}
\hline $\begin{array}{l}\text { Günlük kaç saatinizi internette } \\
\text { geçiriyorsunuz? }\end{array}$ & Frekans & Yüzde (\%) \\
\hline \begin{tabular}{|l|l|} 
& 1 ve daha $a z$ \\
\end{tabular} & 18 & 10,7 \\
\hline $2-3$ saat arası & 73 & 43,5 \\
\hline 4-5 saat arası & 40 & 23,8 \\
\hline 5 saatten fazla & 37 & 22,0 \\
\hline Toplam & 168 & 100,0 \\
\hline
\end{tabular}

Tablo 6. Kullanıcının Günlük Sosyal Medya Kullanım Durumu (Tür Olarak)

\begin{tabular}{|l|l|r|r|}
\hline $\begin{array}{l}\text { En çok kullandığın sosyal medya uygulaması } \\
\text { nedir? }\end{array}$ & Frekans & Yüzde (\%) \\
\hline \multirow{3}{*}{} & Twitter & 121 & 72,0 \\
\cline { 2 - 4 } & İnstagram & 35 & 20,8 \\
\cline { 2 - 4 } & Facebook & 12 & 7,1 \\
\cline { 2 - 4 } & Toplam & 168 & 100,0 \\
\hline
\end{tabular}

Araştırma kapsamında belirlenen öznitelikler kişinin en çok kullandığı sosyal medya uygulaması, hangi tür çevrimiçi oyunları sürekli oynadığı, hangi tür internet sitelerinde sürekli gezindiği, sosyal ağlarda günde ortalama ne kadar zaman geçirdiği, günlük kaç saatinizi internette geçirdiği olarak belirlenmiştir. Yapılan çalışmada bulanık mantık kullanılarak kişinin en çok kullandığı sosyal medya uygulaması, hangi tür çevrimiçi oyunları sürekli oynadığı, hangi tür internet sitelerinde sürekli gezindiği, sosyal ağlarda günde ortalama ne kadar zaman geçirdiğine bakılarak günlük internette geçirdiği vakit hesaplanmaya çalıșılmıștır. Çalıșmada 166 örnek içerisinden \%25'i (N:42) test için 124 tanesi eğitim için kullanılmıştır. Elde edilen değerler Tablo 2. de verilmiştir. (OKH - Ortalama Kare Hata) Yapılan çalışmada başarı oranı \% 91,48 olarak bulunmuştur. 
Tablo 7. Bulanık Mantık Tahmini

\begin{tabular}{|l|l|l|l|}
\hline Băğl Hata & Başarı Yüzdesi & S.Sapma & OKH \\
\hline 0,085202 & 91,47983784 & 0,073357 & 0,4017 \\
\hline
\end{tabular}

Tahmin sonuçlarına göre her bir örneğe göre tahmin edilen derleri ve gerçek değerleri grafik (Şekil 2.) üzerinde görülebilmesini sağlamaktadır. İstenen sonuç ortadaki çizgiye ne kadar yakınsa nokta o kadar bașarılı tahmin edilmiş demektir. Bazı noktalar çakıştığı için örnek sayısı az gibi gözükmekte ve bazı değerlerde üst üste geldiği için gerçek değerler az görünmektedir. Veri sayısının arttı̆̆ı durumlarda bu sorun ortadan kalkmaktadır.

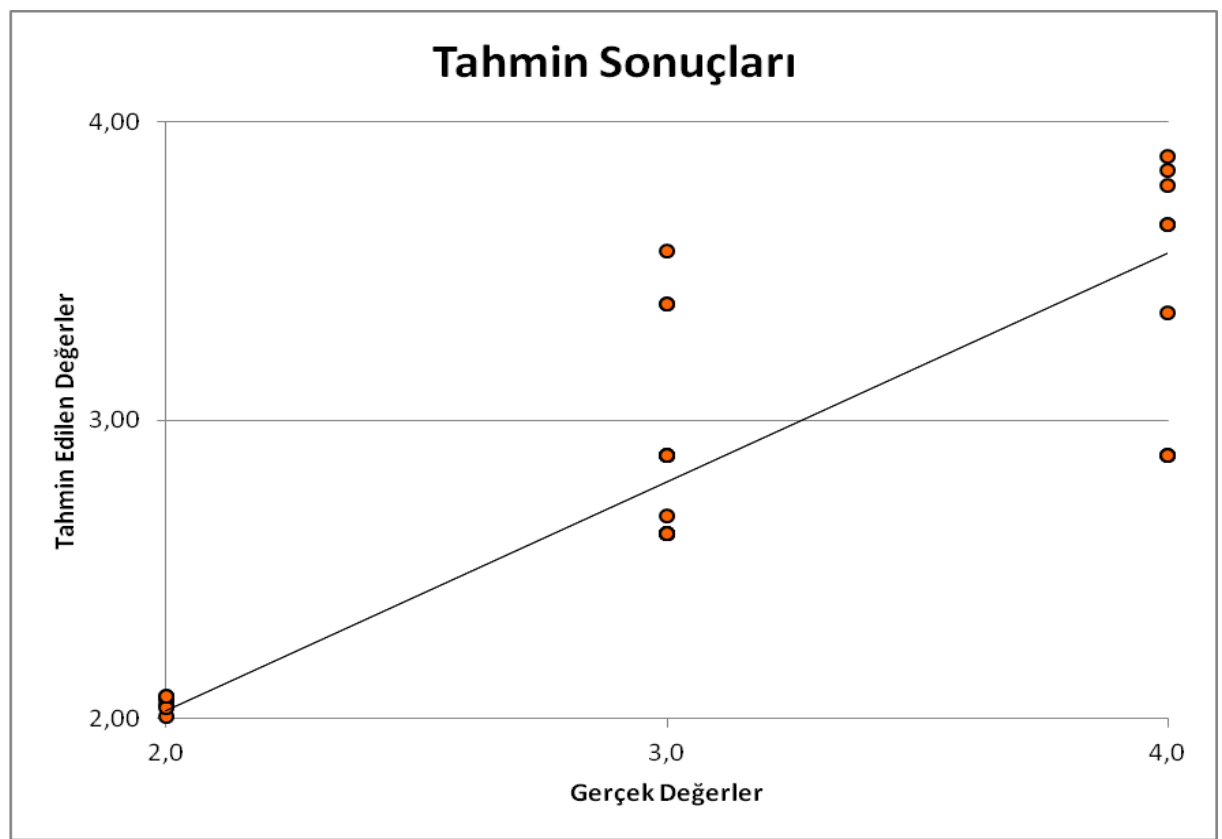

Şekil 2. Tahmin Sonuçları

Kutu grafiği sonucu açıkça görebildiği için önemli bir grafik türüdür, her bir örneğin tahmin başarısını ve ortalama başarı gibi tüm tahmin sonuçlarının tek bir grafikte göstermektedir.

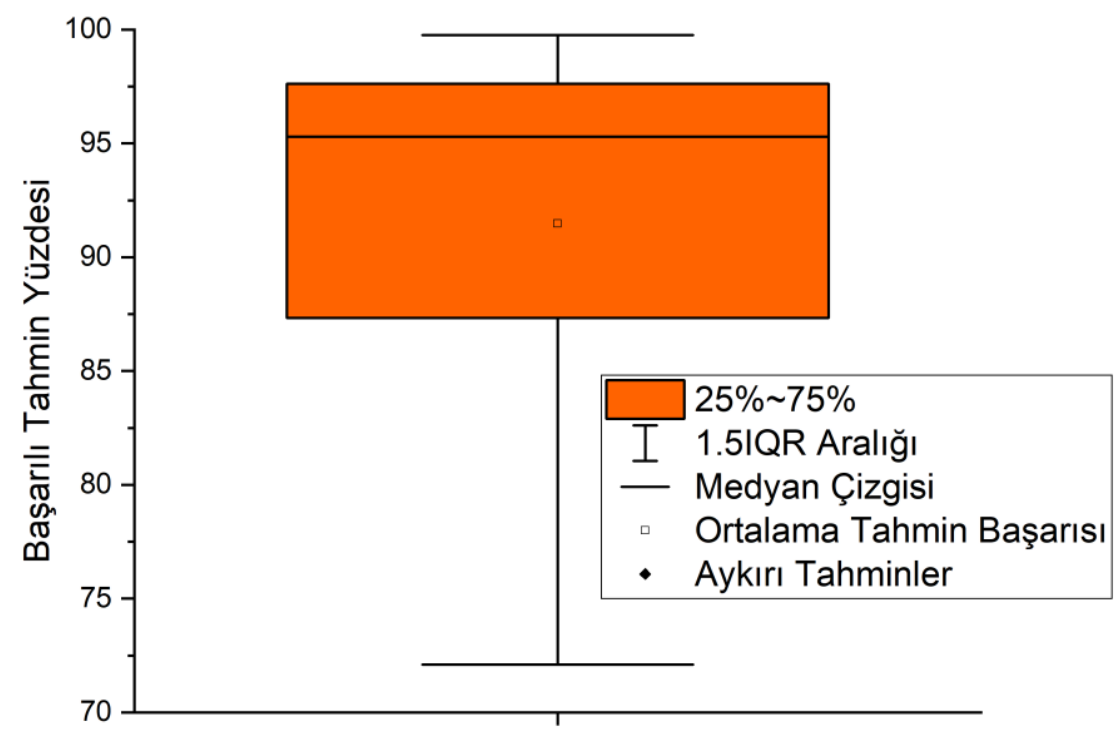

Şekil 3. OKH (Ortalama Kare Hata) Kutu grafiği 


\section{Sonuç (Result)}

Gelișen teknolojik cihazlar insanlığın günlük hayatlarına yenilikler sunmakla birlikte, iletișim çeșitlenmekte ve kolaylaşmaktadır. Bunun yanın da teknolojinin aşırı kullanımı ile de çeşitli sorunlar ortaya çıkmıştır. Teknolojinin bağımlılık yapan maddeler arasında yer alması gerektiği bu konuda da bağımlılık önleyici çalışmaların yapılması gerektiği sonucu ortaya çıkmıştır. Bu alanda da toplumsal farkındalığın arttırılmasına yönelik talep oluşmuştur. Yaşadığımız toplumun farklı katmanlarında (ilkokul, ortaokul, üniversite, aile, iş ortamı) teknoloji bağımlılığıyla mücadele edilmesinin ve çeşitli kurallar getirilmesi gerekmektedir (Ayğar, B. B., ve Uzun, B. 2018). Bu kapsamda BTK (Bilişim Teknolojileri ve iletişim Kurumu) ve Yeşilay teknoloji bağımlılığını önleme ve bağımlılık durumunda yapılması gerenlerle ilgili sosyal sorumluluk projeleri yapmaktadır.

Teknolojinin gelişmesiyle Ekran bașında geçirilen sürenin son yıllarda ciddi oranda artış göstermiștir. Yapılan araştırmada sıradan bir kullanıcı grubunun \%80'inin sabah kalktığında ilk iş olarak cep telefonunu kontrol ettiğini görülmüştür ayrıca kullanıcılar günlük 7-8 saat internette vakit geçirdiği sonucuna ulaşılmıştır (Facebook ve IDC, 2013). Abd'de yapılan bu çalışma Türkiye'de için de geçerli olduğu Tuik verileri ile desteklenmektedir. Günlük internet kullanımı da teknoloji kullanımıyla paralel olarak artış göstermektedir gençler internette geçirilen zamana bağlı olarak bağımlılık durumunda artış gerçekleşmektedir (Ceyhan, Ceyhan ve Gürcan, 2007).

Araştırmacılar tarafından yapılan çalışmalara göre teknoloji kullanımı, interneti kullanım süresi (Durak B, ve Hasta, 2010; Ceyhan, 2011), interneti kullanım amacı (Durak B, ve Hasta, 2010; Ceyhan, 2011), problemli internet kullanımın yordayıcıları olabileceği sonucuna varılmıştır (Akt; Avşar Arık, I. 2018). (Elde edilen sonuca göre öznitelikler kişinin en çok kullandığı sosyal medya uygulaması, Hangi tür çevrimiçi oyunları sürekli oynadı̆̆ı, Hangi tür internet sitelerinde sürekli gezindiği, Sosyal ağlarda günde ortalama ne kadar zaman geçirdiği özniteliklere göre, Günlük kaç saatinizi internette geçirildiği tahmin edilmiştir. Tahmin sonucuna göre \%91 başarı elde edilmiştir. Yapılan çalışmalarda elde edilen sonuçlara göre günlük kullanılan internet miktarının artısı kullanıcının teknoloji bağımlısı olma durumunda etken rol oynadığı görülmüştür. Yapılan çalışmada veriler artırılarak yeni çalışmalar için farklı algoritmalar kullanılabilir ve hibrit algoritma oluşturularak çalışma gerçekleştirilebilinir. Geliştirilen çalıșmalar ile internet kullanıcısının farklı özelikleri göz önünde bulundurularak internet bağımlısı olup olmadığı belirlenebilir.

\section{Çıkar Çatışması (Conflict of Interest)}

Yazarlar tarafından herhangi bir çıkar çatışması beyan edilmemiştir. No conflict of interest was declared by the authors.

\section{Kaynaklar (References)}

Akkaş, İ. (2019). Teknoloji Bağımlılı̆̆ı. Salon Yayınları.

Aktan, E. (2018). Üniversite Öğrencilerinin Sosyal Medya Bağımlılık Düzeylerinin Çeşitli Değişkenlere Göre İncelenmesi. Erciyes İletişim Dergisi, 5(4), 405-421.

Alan, A. Y. (2003). Nisbi Mantık (Fuzzy Logic). International Seminar Group, Ludwigshaven, Germany.

Altaş, İ. H. (1999). Bulanık mantık: Bulanık denetim. Enerji, Elektrik, Elektromekanik-3e, 64(1999), 76-81.

Avşar Arık, I. (2018). Teknoloji Bağımlılı̆̆ı ve Sosyal Kimlik Oluşumu: Y Nesli.

Ayğar, B. B., \& Uzun, B. (2018). Sosyal Medya Bağımlılı̆̆ Ölçeği'nin geliştirilmesi: Geçerlik ve güvenirlik çalışmaları. Addicta: The Turkish Journal on Addictions, 5(3), 1-19.

Beard, K. W., \& Wolf, E. M. (2001). Modification İn The Proposed Diagnostic Criteria For Internet Addiction. Cyberpsychology \& Behavior, 4(3), 377-383.

Dinç, M (2015). Teknoloji Bağımlılığı Ve Gençlik. Gençlik Araştırmaları Dergisi 3: Sayı: 3, 31-65.

Facebook \& IDC. (2013). Study: How addicted are we to Facebook mobile? Retrieved from http:// www.adweek.com/digital/facebook-idc-study-smartphones/

Ikiz Fe, Savci M, Asici E, Yoruk C. Investigation Of Relationship Between Problematic İnternet Use And Psychological Symptoms Of University Students. International Journal Of Human Sciences 2015; 12:688-702. (Turkish)

J Adolesc 2016; 51:41-49. American Psychiatric Association. Diagnostic And Statistical Manual Of Mental Disorders (Dsm-5).Arlington: American Psychiatric Publishing; 2013.

Koçak, Ç. (2018) Bulanık Mantık İle Arı Kovanlarının Uzaktan Takip Ve Kontrol Sistemi, Yüksek Lisans Tezi, Burdur Mehmet Akif Ersoy Üniversitesi.

Kuss, D. J. And Griffiths, M. (2011). Online Social Networking And Addiction-A Review Of The Psychological Literature . International Journal Of Environmental Research And Public Health(8), 3528-3552. Doi:10.3390/İjerph8093528 
Savci, M., \& Aysan, F. (2017). Technological Addictions And Social Connectedness: Predictor Effect Of İnternet Addiction, Social Media Addiction, Digital Game Addiction And Smartphone Addiction On Social Connectedness. Dusunen Adam: Journal Of Psychiatry \& Neurological Sciences, 30(3), 202-216.

Shaw, M., \& Black, D. W. (2008). Internet addiction. CNS drugs, 22(5), 353-365.

Twenge, J. M. (2017). Have smartphones destroyed a generation. The Atlantic, 9, 2017.

Woods Hc, Scott H. Sleepyteens: Social Media Use İn Adolescence İs Associated With Poor Sleep Quality, Anxiety, Depression And Low Self-Esteem. 